\title{
Mechanical Performance of Hammersmith Mitral Valve Prosthesis
}

\author{
E. B. RAFTERY ${ }^{\star}$, M. K. A. DAYEM, AND D. G. MELROSE \\ From the Department of Medicine (Clinical Cardiology), and The Nuffield Unit of Clinical Physiology, \\ Royal Postgraduate Medical School of London, and Hammersmith Hospital, London W.12
}

The basic mechanical requirements of a successful mitral valve prosthesis are first, that it should not present any significant obstruction to flow from the left atrium to the left ventricle; secondly, that it should be fully competent under its working conditions (including exercise); and thirdly, that it should not interfere with the normal events of left ventricular contraction.

The Hammersmith mitral valve prosthesis was designed to meet these requirements and provide an adequate substitute for the natural mitral valve apparatus. This paper presents the results of investigations conducted to establish how well the prosthesis meets these requirements, both in vitro and in vivo.

\section{SUBJECTS AND METHODS}

The Hammersmith mitral valve prosthesis has been fully described by Melrose $e t$ al. (1964). It consists of a ring from which a trapdoor is suspended by a number of short legs. The whole structure is moulded from polypropylene, a plastic material which is biologically inert, has great tensile strength, and takes a very high polish. The basic advantage of this type of design is that no part of the valve, is left within the cavity of the left ventricle during systole, and so it cannot offer mechanical resistance to left ventricular contraction. Several designs (Marks I, II, and III) have been produced, with the object of improving the hydraulic qualities of the valve and decreasing the surface area which might be available for clot formation (Fig. 1).

The Mark I valve was used as a prototype in animal experiments for the development of Mark II, which was the first type to be used in human beings. The trapdoor of the Mark II valve was much lighter and was

\footnotetext{
Received September 4, 1967.

* Present address: Cardiac Department, King's College Hospital, London S.E.5.
}

suspended from the ring by only two legs. This arrangement allowed a much wider orifice during diastole, but the valve had to be very accurately placed in the heart so that the trapdoor opened into the left ventricular outflow tract, because one side was completely occluded when the trapdoor was open (Fig. 1). The modifications introduced with the Mark III valve ensured an opening all around the trapdoor, and made the positioning of the valve less than critical.

\section{Experimental Observations}

Obstruction to Flow. The valve was mounted between a wide-bore tube and a large chamber so that it opened into the chamber (Fig. 2). The system was then perfused with tap-water at measured steady flow-rates, and pressure was measured from mid-stream on both sides of the valve by means of strain gauges (Statham P23Gb) and a photographic recorder (New Electronic Products). Flow was varied from 1-26 1./min., and from these data pressure gradient/flow curves were constructed. Families of curves were constructed for the different sizes of each type of valve.

Valve Competence. Polypropylene is very light and has a lower specific gravity than blood $(0 \cdot 9: 1 \cdot 050)$, so there should be very little delay in movement of the trapdoor from the wide-open to the shut position at the beginning of left ventricular systole. Any delay in movement could result in regurgitation through the valve orifice. This was tested with the same experimental apparatus by measuring pressure on both sides of the valve without any flow, and then suddenly applying a large pressure to the distal side of the valve. The pressure tracings gave a good estimate of the time the trapdoor takes to travel from the wide-open to the closed position.

In addition, the valve was mounted in a simple plastic tube and connected to a pulse duplicator (McMillan, 1955). A cine film was taken at 100 frames per second and the time taken for the trapdoor to reach its open and closed positions was recorded. 
Mk I
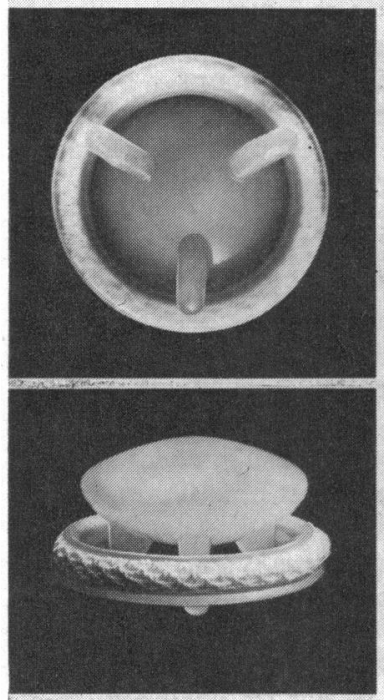

Mk II
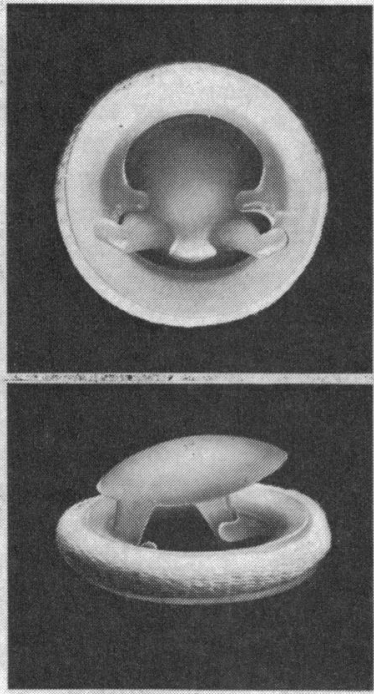

Mk III
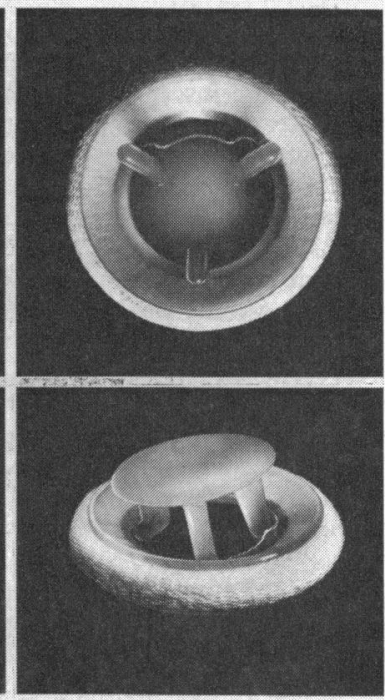

Fig. 1.-Elevation and plan views of the three types of Hammersmith mitral valve prosthesis. Mark I had three legs of equal length supporting a large trapdoor. Mark II had only two legs and a trapdoor which opened to one side only. Mark III has three legs, two long and one short, so that the trapdoor opens all around its circumference.

\section{Observations in Patients}

Eight patients with Hammersmith mitral valve prostheses were studied at intervals ranging from 1 to 15 months after operation. Five of these patients had shown a conspicuous improvement, and were virtually asymptomatic. One (F.L.) had improved but still had moderate exertional dyspnoea. Two (B.B. and M.B.) had shown little improvement and had soft apical systolic murmurs which suggested that the valve might be incompetent.

Obstruction to Flow. All these patients had a right heart catheterization. In addition, a catheter was

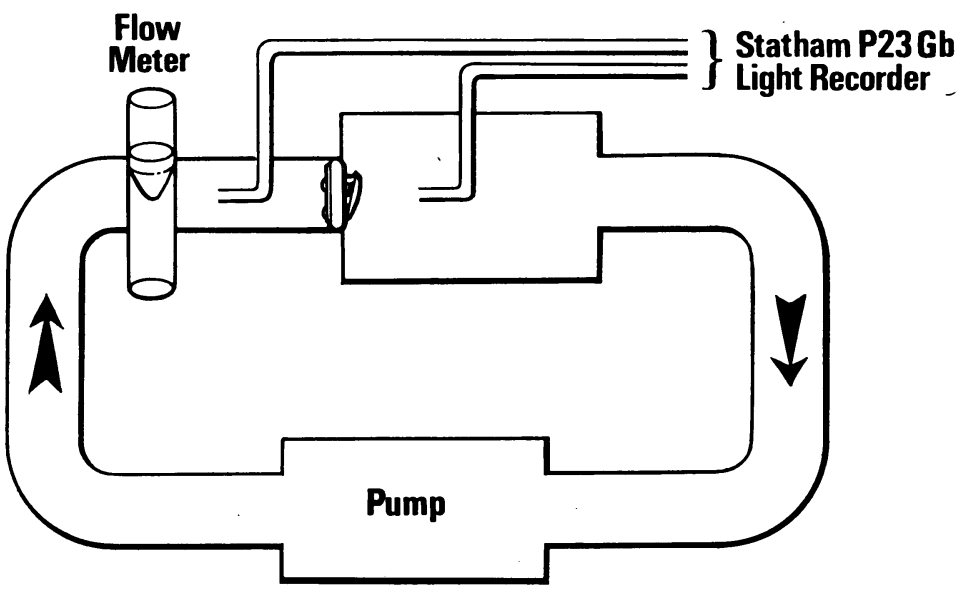

Fig. 2.-Diagram to illustrate the apparatus used to determine the pressure/flow relationships of the valve in vitro. Arrows indicate the direction of flow. 
passed by the transseptal technique to the left atrium, and another catheter from a right brachial arteriotomy to the left ventricle. Pressures were recorded by means of matched strain gauges (Statham P23Gb) and a photographic recorder (Electronics for Medicine). Simultaneous dye curves were inscribed using Cardio-Green (Gilford densitometer and Cuvette) injected into the pulmonary artery and sampled from the femoral artery. A phonocardiogram was recorded at the same time. This was repeated after exercise or infusions of isoprenaline.

From the pressure tracings, the mean diastolic gradient between the left atrium and left ventricle was obtained by planimetry. Cardiac output was obtained from the dye curve, and the length of diastole in each cycle from the phonocardiogram; from these data the mean diastolic flow across the mitral valve was calculated.

Curves of mean pressure gradient against mean diastolic flow were then constructed for the 6 patients with competent valves.

Valve Competence. Left ventricular cine-angiograms were performed in all patients. In three, valve competence was also tested by injecting indocyanine green into the left ventricle and sampling from the left atrium. In one patient (A.T.) this was repeated after infusion of isoprenaline.

Relation to Left Ventricular Contraction. The left ventricular cine-angiograms were closely analysed to show the relations of the trapdoor and its movement during left ventricular systole.

\section{Results}

\section{Experimental Observations.}

Fig. 3 shows the families of pressure gradient/ flow curves for Mark II and Mark III valves. The performance of the Mark I valve is not considered because it was so inferior to the later designs.

The size of the pressure gradient in these curves is a measure of the amount of obstruction presented by the valve apparatus. It is clear that increasing the internal diameter of the Mark II valve above $2.25 \mathrm{~cm}$. produced no significant improvement in hydraulic performance. On the other hand, while the $2 \mathrm{~cm}$. Mark III valve had much the same hydraulic characteristics as the $2 \mathrm{~cm}$. Mark II valve, increasing the internal diameter above $2 \mathrm{~cm}$. produced a distinct improvement in performance. Thus, a pressure gradient of $8 \mathrm{~mm}$. $\mathrm{Hg}$ was produced by a flow of $18 \mathrm{l} . / \mathrm{min}$. across the Mark II $2.25 \mathrm{~cm}$. valve, but the gradient across the equivalent Mark III valve was only $5 \mathrm{~mm}$. $\mathrm{Hg}$.

Valve Competence. Fig. 4 shows pressure curves taken to test valve competence. It can be seen that when sudden pressure is applied distal to the valve, there is a pressure rise proximal to the valve which is cut off abruptly after 10-15 msec., suggesting that this is the travel time for closure. These observations were confirmed by examination of the film of the valve, in the pulse duplicator.

\section{Observations in Patients}

Obstruction to Flow. Table I summarizes the pre- and post-operative catheter findings in these patients. Five patients had Mark II valves (two $2 \mathrm{~cm}$. and three $2.5 \mathrm{~cm}$. internal diameter), and three had Mark III valves (two $2 \mathrm{~cm}$. and one $2 \cdot 25 \mathrm{~cm}$.
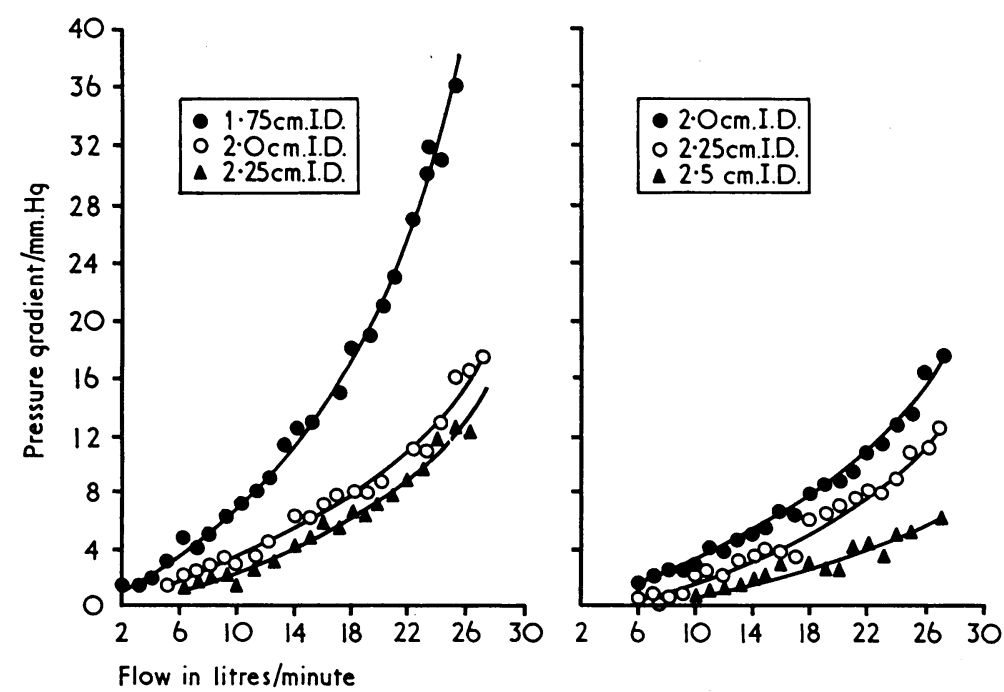

FIG. 3.-Pressure gradient/flow relationship for the different sizes of Mark III and Mark II valves. Note the marked decrease in gradient even with high flows in the large sizes of the Mark III valve. 
MARK II

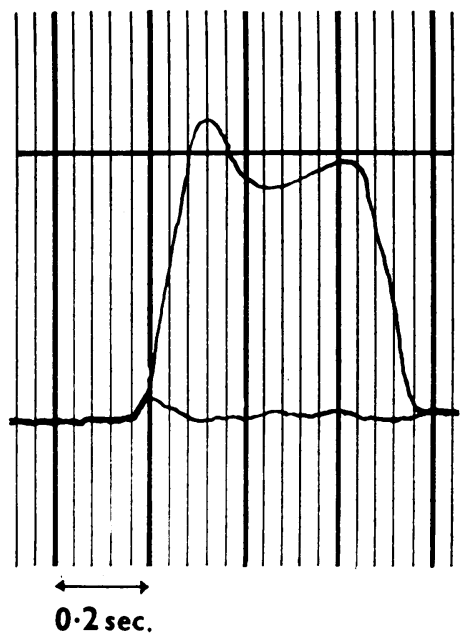

MARK III

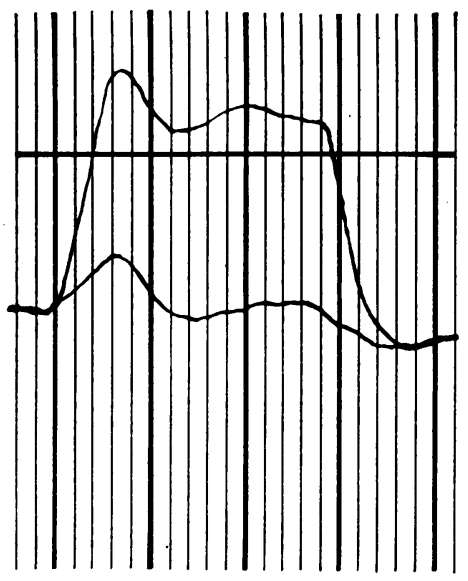

Fig. 4.-Pressures taken from both sides of the valve mounted in the perfusion chamber shown in Fig. 2 . When a large pressure was suddenly applied to the chamber, the pressure rose on both sides of the valve. However, when the valve was completely closed, pressure on the distal side abruptly fell. The time interval between initial pressure rise and this cut-off point was $15 \mathrm{msec}$. This suggests that the trapdoor takes 15 msec. to close, and this was confirmed by timing movement on a cine film.

internal diameter). It can be seen that in all patients the data were closer to normal after operation. Three patients (F.L., B.B., and M.B.) showed only moderate clinical improvement; in two of these (B.B. and M.B.) mitral incompetence was shown. In the third patient (F.L.) a very high resting left atrial pressure was found, and this suggested considerable mitral stenosis.
Table II shows the mean gradients and diastolic flows calculated before and after isoprenaline infusion in six patients. These data are shown again in Fig. 5 where the patients are grouped according to their type and size of valve. The data obtained from the patients are superimposed upon the pressure gradient/flow curve obtained for the same type and size of valve in the experimental situation. It

TABLE I

CATHETER DATA BEFORE AND AFTER OPERATION

8 PATIENTS WITH HAMMERSMITH MITRAL VALVE PROSTHESES. PRESSURES IN MM. HG

\begin{tabular}{|c|c|c|c|c|c|c|c|c|c|c|c|c|c|c|c|c|}
\hline \multirow{2}{*}{$\begin{array}{l}\text { Patient's } \\
\text { initials }\end{array}$} & \multirow{2}{*}{$\begin{array}{l}\text { Age } \\
(y r .)\end{array}$} & \multirow{2}{*}{ Sex } & \multirow{2}{*}{$\begin{array}{c}\text { Valve type } \\
\text { and size } \\
(\mathrm{cm} .)\end{array}$} & \multirow{2}{*}{$\begin{array}{l}\text { Months } \\
\text { post-op. }\end{array}$} & \multicolumn{6}{|c|}{ Pre-operative } & \multicolumn{6}{|c|}{ Post-operative } \\
\hline & & & & & PCW & LA & PA & LV & PAR & CI & PCW & LA & PA & LV & PAR & CI \\
\hline F.L. & 50 & F & II 2.5 & 7 & $\begin{aligned} v & =31 \\
m & =19\end{aligned}$ & 一 & $\begin{array}{l}60 / 30 \\
m=39\end{array}$ & $100 / 20$ & $5 \cdot 0$ & $2 \cdot 5$ & - & $\begin{aligned} v & =27 \\
m & =22\end{aligned}$ & $\begin{array}{l}38 / 20 \\
m=25\end{array}$ & $125 / 11$ & 0.3 & $2 \cdot 0$ \\
\hline v.w. & 25 & $\mathbf{F}$ & II $2 \cdot 5$ & 15 & $\begin{aligned} v & =66 \\
m & =31\end{aligned}$ & - & $\begin{array}{l}65 / 27 \\
\mathrm{~m}=44\end{array}$ & $90 / 27$ & $3 \cdot 4$ & $2 \cdot 6$ & - & $\begin{array}{l}\mathrm{v}=7 \\
\mathrm{~m}=5\end{array}$ & $\begin{array}{l}25 / 9 \\
\mathrm{~m}=12\end{array}$ & $130 / 5$ & $1 \cdot 8$ & $2 \cdot 6$ \\
\hline J.K. & 23 & F & II 2 & 9 & $\begin{aligned} v & =60 \\
\mathrm{~m} & =32\end{aligned}$ & - & $\begin{array}{l}54 / 32 \\
\mathrm{~m}=45\end{array}$ & $105 / 10$ & $5 \cdot 7$ & $1 \cdot 4$ & - & $\begin{array}{l}\mathrm{v}=25 \\
\mathrm{~m}=16\end{array}$ & $\begin{array}{l}31 / 12 \\
\mathrm{~m}=19\end{array}$ & $112 / 11$ & 0.6 & $3 \cdot 0$ \\
\hline J.F. & 31 & $\mathbf{F}$ & II 2 & 11 & $\begin{array}{l}v=24 \\
\mathrm{~m}=19\end{array}$ & - & $\begin{array}{l}50 / 20 \\
\mathrm{~m}=30\end{array}$ & - & $3 \cdot 4$ & $2 \cdot 8$ & - & $\begin{array}{l}v=21 \\
\mathrm{~m}=20\end{array}$ & - & $140 / 15$ & - & $3 \cdot 4$ \\
\hline L.W. & 49 & F & III 2 & 4 & $\begin{array}{l}\mathrm{v}=20 \\
\mathrm{~m}=16\end{array}$ & - & $\begin{array}{l}35 / 20 \\
\mathrm{~m}=25\end{array}$ & $110 / 20$ & 3.9 & $2 \cdot 3$ & - & $\begin{array}{l}v=17 \\
\mathbf{m}=13\end{array}$ & $\begin{array}{l}37 / 22 \\
\mathrm{~m}=27\end{array}$ & $97 / 10$ & $2 \cdot 6$ & $3 \cdot 2$ \\
\hline A. $T$. & 17 & F & III 2 & 4 & - & 一 & - & - & 一 & - & - & $\begin{array}{l}v=13 \\
m=11\end{array}$ & $\begin{array}{l}38 / 12 \\
m=22\end{array}$ & $114 / 15$ & 1.5 & $5 \cdot 1$ \\
\hline M.B. & 48 & $\mathbf{F}$ & III $2 \cdot 25$ & 1 & $\begin{array}{r}\mathrm{v}=42 \\
\mathrm{~m}=38\end{array}$ & - & $\begin{array}{l}67 / 37 \\
\mathrm{~m}=45\end{array}$ & $130 / 20$ & $8 \cdot 2$ & $2 \cdot 6$ & - & $\begin{aligned} v & =60 \\
m & =37\end{aligned}$ & $\begin{array}{l}85 / 35 \\
\mathrm{~m}=60\end{array}$ & $105 / 20$ & $3 \cdot 6$ & $3 \cdot 0$ \\
\hline B.B. & 56 & F & II 2.5 & 2 & $\begin{array}{l}\mathrm{v}=65 \\
\mathrm{~m}=32\end{array}$ & - & $\begin{array}{l}75 / 35 \\
\mathrm{~m}=55\end{array}$ & $140 / 30$ & $8 \cdot 9$ & $2 \cdot 6$ & $\begin{aligned} v & =42 \\
\mathrm{~m} & =31\end{aligned}$ & $=$ & $\begin{array}{l}88 / 32 \\
\mathrm{~m}=55\end{array}$ & $145 / 17$ & $6 \cdot 1$ & $2 \cdot 3$ \\
\hline
\end{tabular}

PCW, pulmonary capillary wedge; LA, left atrium; PA, fulmonary artery; LV, left ventricle; PAR, pulmonary arteriolar resistance (absolute units); $\mathrm{CI}$, cardiac index; $\mathrm{m}=$ mean; $\mathrm{v}={ }^{\prime} \mathrm{V}$ ' wave. 
TABLE II

DATA FOR IN VIVO PRESSURE GRADIENT/FLOW CURVES IN 5 PATIENTS

\begin{tabular}{|c|c|c|c|c|c|c|c|c|c|c|c|c|c|c|c|c|c|c|}
\hline & \multicolumn{18}{|c|}{ Patient's initials } \\
\hline & \multicolumn{2}{|c|}{ V.W. } & \multicolumn{3}{|c|}{ J.K. } & \multirow{2}{*}{$\frac{\text { J.F. }}{1}$} & \multirow{2}{*}{$\frac{\text { F.L. }}{1}$} & \multicolumn{4}{|c|}{ L.W. } & \multicolumn{7}{|c|}{ A.T. } \\
\hline & 1 & $2 t$ & 1 & 2 & $3 \star$ & & & 1 & $2 \star$ & $3 \star$ & $4^{\star}$ & 1 & $2 \star$ & $3 *$ & $4^{\star}$ & $5^{\star}$ & $6 \star$ & $7 \star$ \\
\hline Cardiac output & 3.98 & $6 \cdot 82$ & $4 \cdot 33$ & 3.90 & $9 \cdot 51$ & $4 \cdot 12$ & 3.55 & $5 \cdot 52$ & 8.43 & $10 \cdot 21$ & $7 \cdot 74$ & $7 \cdot 34$ & $12 \cdot 01$ & 11.52 & $8 \cdot 43$ & $7 \cdot 45$ & $11 \cdot 47$ & 10.57 \\
\hline $\begin{array}{l}\text { Heart rate } \\
\text { (beats/min.) }\end{array}$ & 80 & 104 & 61 & 59 & 125 & 106 & 160 & 81 & 98 & 128 & 136 & 88 & 145 & 129 & 92 & 122 & 132 & 114 \\
\hline $\begin{array}{l}\text { Diastolic time } \\
\text { (\%cycle time) }\end{array}$ & 42 & 33 & 56 & 56 & 33 & 30 & 46 & 47 & 48 & 50 & 48 & 42 & 40 & 42 & 42 & 47 & 44 & 45 \\
\hline $\begin{array}{l}\text { Mean diastolic } \\
\text { gradient }(\mathrm{mm} . \mathrm{Hg})\end{array}$ & 2 & 13 & 3 & 3 & 14 & 3 & 18 & 5 & 11 & 13 & 12 & 5 & 10 & 13 & 6 & 7 & & 8 \\
\hline $\begin{array}{l}\text { Calculated diastolic } \\
\text { flow (1./min.) }\end{array}$ & $8 \cdot 7$ & $21 \cdot 2$ & $7 \cdot 7$ & $7 \cdot 0$ & $28 \cdot 6$ & 12 & $9 \cdot 5$ & $12 \cdot 0$ & $18 \cdot 2$ & $20 \cdot 4$ & $16 \cdot 2$ & $17 \cdot 6$ & $28 \cdot 5$ & $27 \cdot 2$ & $20 \cdot 1$ & $15 \cdot 4$ & $26 \cdot 1$ & $23 \cdot 2$ \\
\hline $\begin{array}{l}\text { Valve type and } \\
\text { size }\end{array}$ & \multicolumn{2}{|c|}{$\begin{array}{l}\text { Mark II } \\
2.5 \mathrm{~cm} .\end{array}$} & \multicolumn{3}{|c|}{ Mark II $2.0 \mathrm{~cm}$. } & $\begin{array}{l}\text { Mark } \\
\text { II } \\
2.0 \mathrm{~cm}\end{array}$ & $\begin{array}{c}\text { Mark } \\
\text { II } \\
2.5 \mathrm{~cm}\end{array}$ & \multicolumn{4}{|c|}{ Mark III $2.0 \mathrm{~cm}$. } & \multicolumn{7}{|c|}{ Mark III $2.0 \mathrm{~cm}$} \\
\hline
\end{tabular}

$\star$ After isoprenaline infusion.

t After exercise.

can be seen that in all but one of the patients, the pressure gradient/flow relationships obtained in the body approximate closely to the experimental curve. The exception (F.L.) is the patient with a high post-operative left atrial pressure. A left ventricular angiogram on this patient showed that the valve had not been inserted correctly, and the trapdoor did not open directly into the left ventricular outflow tract. The net result was considerable obstruction to flow, which was re- flected in the high resting pressure and diastolic gradient.

Fig. 6 shows typical pressures taken from two of these patients before and after infusions of isoprenaline. It can be seen that while the diastolic gradient across the valve increased, the left atrial pressure did not rise to any great degree. One patient (L.W.) developed a systolic murmur (Fig. 6) after isoprenaline, but dye curves did not suggest mitral incompetence.
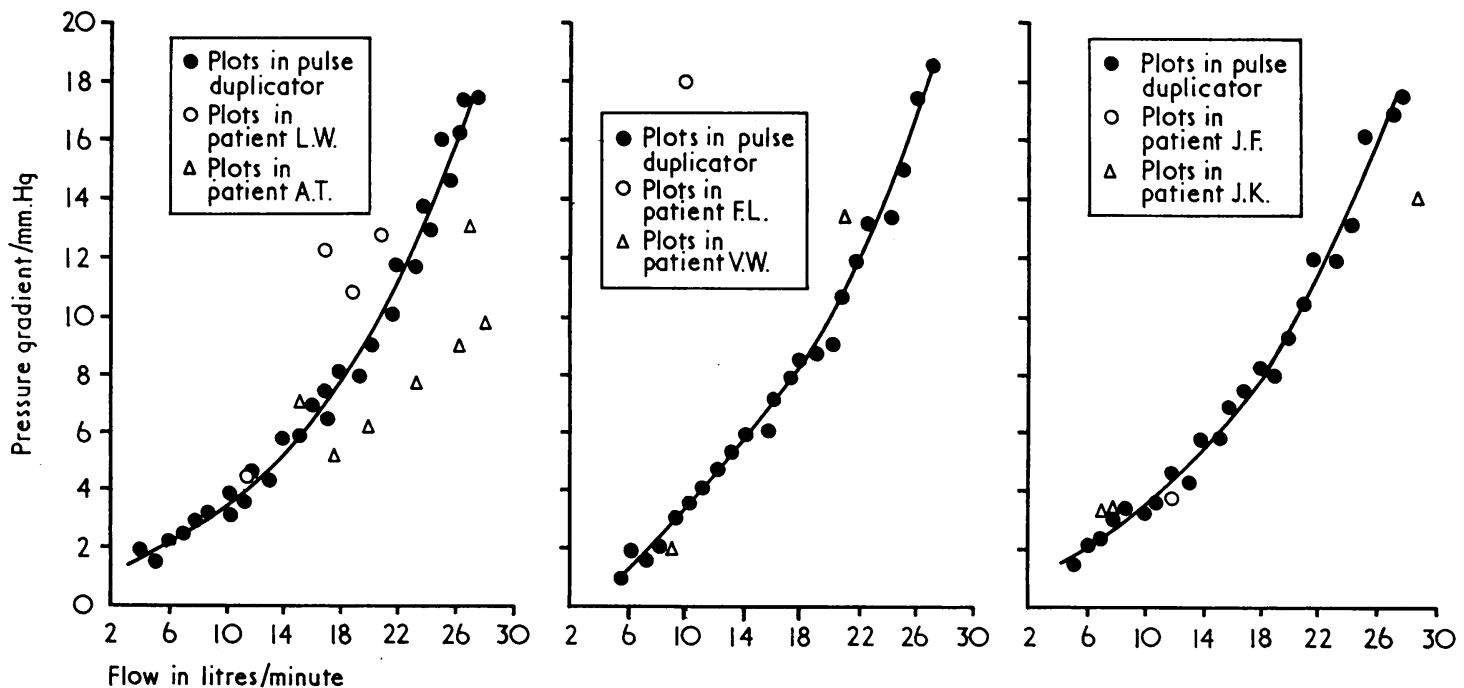

Fig. 5.-Pressure gradient/flow curves for different sizes of the prosthesis obtained by in vitro experiments. Superimposed on the curves are points taken from observations made in patients with the same size and type of valve. It can be seen that the in vivo observations approximated closely to the experimental curves, suggesting that the performance of the valve in the beating heart was similar to that observed on the laboratory bench. 


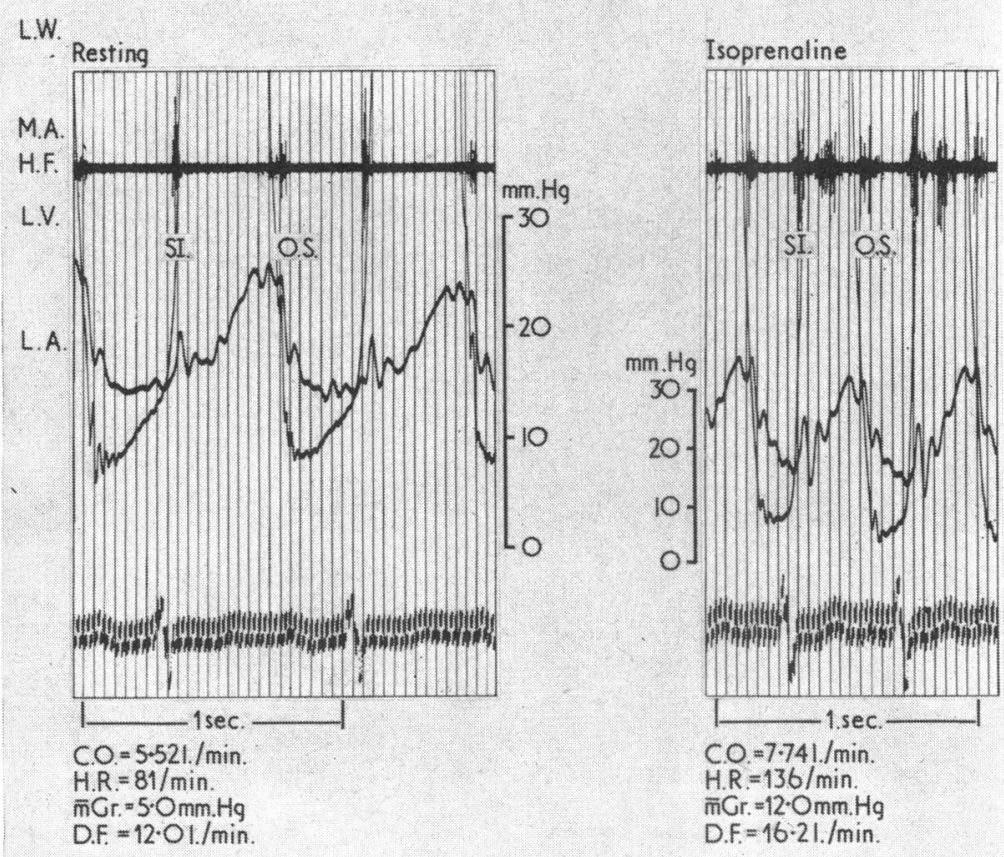

FIG. 6.-Pressures recorded during the determination of cardiac output before and after infusion of isoprenaline in a patient with a Mark III prosthesis. Note that though there was a considerable increase in cardiac output and heart rate, with a consecutive increase in mean gradient, the general level of left atrial pressure did not rise, and the patient was not distressed. The left atrial tracing shows a much larger "a" wave after isoprenaline. Dye curves, injecting in the left ventricle, and sampling from the left atrium, both at rest and after isoprenaline, did not suggest any valve incompetence.

Valve Competence. Dye curves and left ventricular cine-angiograms (Fig. 7) confirmed that the valve was fully competent in six of these patients. In two, mitral incompetence was suspected after operation, because they failed to show much clinical improvement. Left ventricular angiograms confirmed that the valve was incompetent in both cases. In one (M.B.) the catheter was readily passed from left ventricle to left atrium, with no change in the audible heart sounds or increase in the intensity of the murmur. From this it was inferred that incompetence was due to dehiscence of the valve ring rather than to failure of the trapdoor mechanism, and this was shown to be the case at operation. In the second patient (B.B.) the mechanism of incompetence was found at operation to be similar.

In both these patients the systolic murmur was quite soft and was not a useful clue to the presence of incompetence or its mechanism. This was illustrated during catheterization of a patient with a competent valve (L.W.) when the catheter passed from the left ventricle to the left atrium through the trapdoor. Severe mitral incompetence was pro- duced, but the patient did not develop a systolic murmur, and there was no change in the sounds produced by the valve prosthesis (Fig. 8).

Relation to Left Ventricular Contraction. The cine-angiograms confirmed that no part of the valve mechanism remained in the cavity during systole (Fig. 7) and so there was no possibility of interference with the mechanics of contraction. Since the valve is positioned so that it opens into the left ventricular outflow tract, it was feared that as the heart decreased in size, the interventricular septum might come to impinge upon the lip of the trapdoor when it was open. In every patient the trapdoor returned smartly to the closed position, and there was no evidence that it impinged upon the myocardium or interfered with its contraction in any way. However, the valve cannot open properly unless it is placed to open into the outflow tract, as illustrated by patient F.L. (Fig. 9).

\section{Discussion}

Mitral valve prostheses of the trapdoor and ball- 


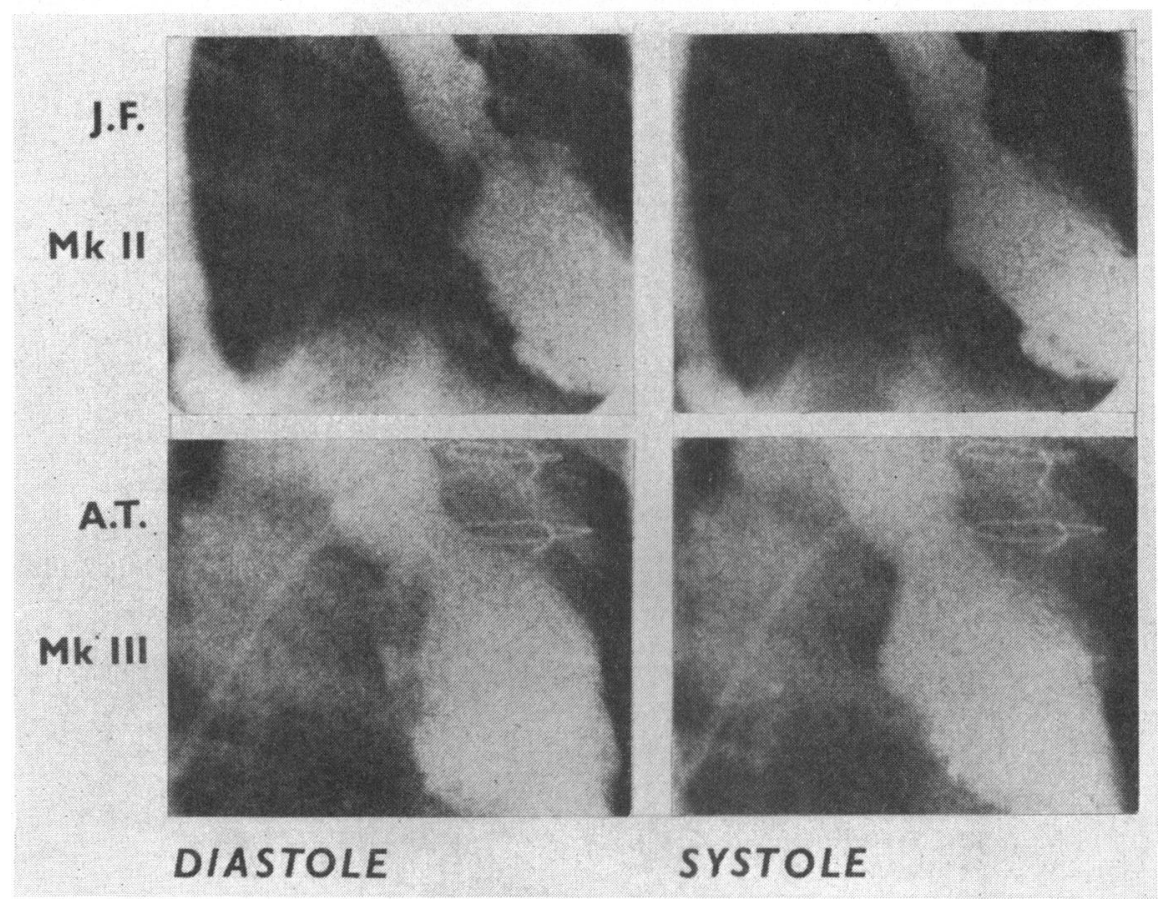

FIG. 7.-Frames taken from left ventricular cine-angiograms in patients with Mark II and Mark III prostheses. Right anterior oblique position. Note that the valve opens directly into the left ventricular outflow tract, but that the lower edge of the Mark II valve is closed while the Mark III valve projects completely into the ventricle. No part of the valve remained behind in the ventricle during systole, and there is no indication that the trapdoor impinges upon the interventricular septum. The left atrium lies within the arch of the aorta in this projection, and there is no indication of incompetence during systole.

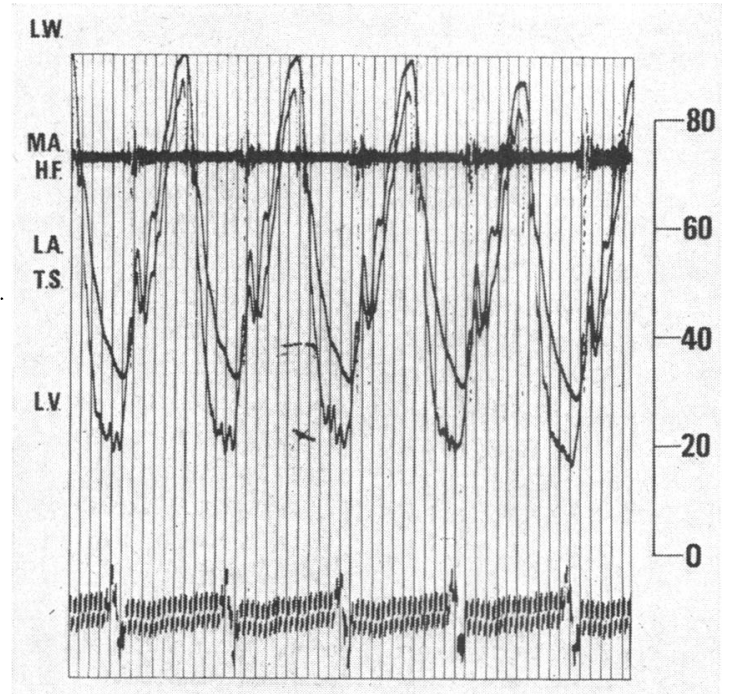

FIG. 8.- Simultaneous pressures recorded from the left atrium, one by means of a transseptal catheter, and the other by means of a catheter passed from the left ventricle through the orifice of the trapdoor. Note that the sounds produced by the prosthesis retained their usual quality and intensity, and that there was only a soft early systolic murmur. A dye curve inscribed at this time suggested very severe mitral incompetence. 


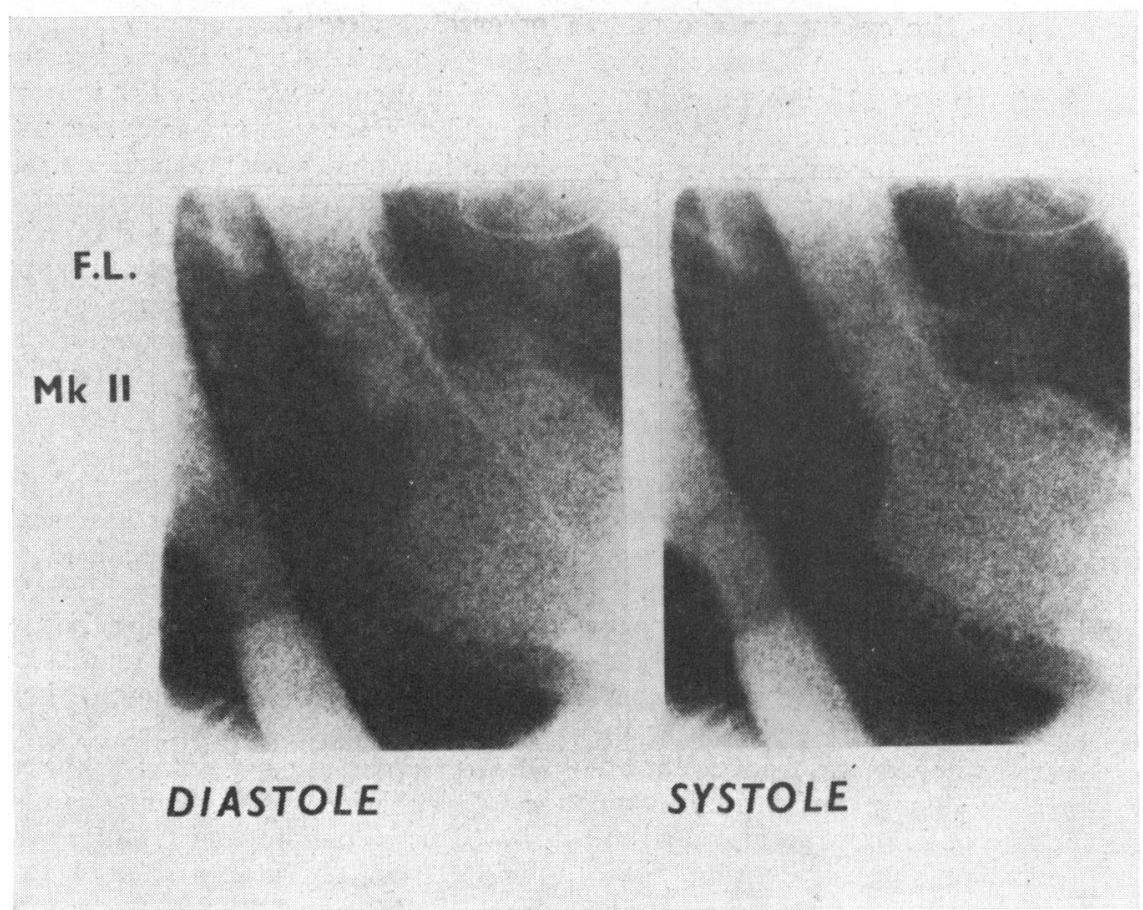

FIG. 9.-Frames taken from a left ventricular cine-angiogram in a patient with a Mark II prosthesis and evidence of severe obstruction. The trapdoor did not appear to open directly into the outflow tract (compare with Fig. 8), suggesting that it had been inserted at an angle of $90^{\circ}$ to the desired position. Since the type of valve did not open all around its circumference, this resulted in a competent, but stenotic valve. Right anterior oblique projection.

and-cage varieties must present some obstruction to flow between the left atrium and left ventricle, because part of the valve mechanism sits in the centre of the stream throughout diastole. The chief disadvantage of the ball-and-cage design is that the cage occupies space within the ventricle, and erosion and perforation of the myocardium are distinct possibilities (Hughes, 1965). This cannot happen with the trapdoor design, and the angiograms on these patients confirm that there is no interference with the mechanics of ventricular systole. Obstruction to flow is minimized if the trapdoor can open widely, and it was with this in mind that the Mark II valve was designed. However, this valve had to be placed very accurately within the heart so that the trapdoor opened into the left ventricular outflow tract. If it were not accurately placed, considerable stenosis could result, and this was clearly shown in the study of patient L.F. Hence the Mark III valve, with three legs, two long and one short. This ensures that the valve opens all around the edge of the trapdoor, but the opening is still eccentric and there is a wide area for flow, with a minimal degree of obstruction.
Experiments performed outside the body can never reproduce exactly the working conditions of the valve in the functioning heart. Steady-state flow is easy to produce in a mechanical model, but is never seen in the beating heart, where flow across the mitral valve varies continuously throughout diastole. However, our results show that careful measurement of the mean pressure gradients and diastolic flow yields results that are similar to those found in the experimental situation. Thus, it would be fair to deduce that if relatively crude testing of this kind indicates that a valve is suitable for use as a prosthesis, these data will apply to working conditions in vivo, with an acceptable degree of accuracy. The experimental results with this valve suggested that it would present very little obstruction to flow, and this has proved to be the case.

Thus, in the normal subject a mean diastolic flow across the mitral valve of $101 . / \mathrm{min}$. is required to produce a cardiac output of $61 . / \mathrm{min}$., with a heart rate of 70 beats a minute (Lombard and Cope, 1919). Flow rates of this degree can be achieved with the Mark II and Mark III $2.25 \mathrm{~cm}$. valves at a cost of a gradient of $3 \mathrm{~mm} . \mathrm{Hg}$ and $2 \mathrm{~mm}$. $\mathrm{Hg}$. 
During exercise the cardiac output can rise to 15 1./min., which would require a mean diastolic flow of $26 \mathrm{l}$./min., at a heart rate of 115 beats a minute. This is achieved with the Mark II and Mark III $2.25 \mathrm{~cm}$. valves at a cost of a mean gradient of 16 $\mathrm{mm} . \mathrm{Hg}$ and $11 \mathrm{~mm}$. Hg. Mean gradients of this degree can probably be disregarded, and certainly do not seem to be of importance in patients with valve prostheses. Hence the fact that, though gradients could easily be produced by increasing diastolic flow, the mean level of left atrial pressure rose very little and the patients showed no evidence of distress.

However, the studies in patients showed that the Mark II valve could present considerable obstruction if it were not properly positioned, and this suggested a useful modification of the valve design.

Direct comparisons between the hydraulic properties of the Hammersmith prosthesis and other prostheses are not easy because there are so few comparable data. Kezdi, Head, and Buck (1964) published pressure gradient/flow curves from the StarrEdwards prostheses of $1.45 \mathrm{~mm}$. and $2 \mathrm{~cm}$. internal diameter. A flow rate of $91 . / \mathrm{min}$. produced gradients of $7 \mathrm{~mm}$. $\mathrm{Hg}$ and $3 \mathrm{~mm}$. $\mathrm{Hg}$, respectively. The gradient with the Mark III $2 \mathrm{~cm}$. internal diameter valve at this flow rate was $3 \mathrm{~mm}$. Hg. Morrow et al. (1964) found that the $2 \mathrm{~cm}$. internal diameter Starr-Edwards valve produced a gradient of $7 \mathrm{~mm}$. $\mathrm{Hg}$ at a flow rate of $141 . / \mathrm{min}$.; the gradient with the Mark III $2 \mathrm{~cm}$. at $14 \mathrm{l} . / \mathrm{min}$. was $5 \mathrm{~mm}$. Hg. These figures suggest that the Hammersmith prosthesis is similar to the Starr-Edwards prosthesis on testing in vitro. However, both Kezdi et al. (1964) and Morrow et al. (1964) found that the gradients developed in vivo were considerably larger, and suggested that factors such as inertia of the ball were responsible. The results of our in vivo observations agree closely with the in vitro observations, and the gradients were often less than those observed in the experimental situation.

The time taken for opening and closing of the trapdoor is comparable with the time taken by the normal mitral valve (Faber, 1964). There is no reason why such a valve should be incompetent, and the left ventricular cineangiograms and dye curves showed that it is indeed competent under its working conditions. Both the cases of post-operative incompetence were due to dehiscence of stitches around the valve ring, and not to failure of the trapdoor mechanism. The murmur associated with the mitral incompetence in these cases was curious in that it was very soft. This is the same finding as that of Morrow et al. (1964). Even severe incompetence produced by passing a catheter from left ventricle to left atrium failed to produce a murmur, or even to alter the quality of the heart sounds. Thus it seems that the most important feature in assessing the presence of mitral incompetence after operation is not that normally associated with this lesion in patients with natural mitral valves, but failure to maintain clinical improvement in terms of exertional dyspnoea, and lack of changes in the chest $x$-ray towards a more normal appearance. In both these patients normal function was restored by a second operation and resuture of the valve ring.

\section{SUMMARY}

The mechanical performance of the Hammersmith mitral valve prosthesis has been assessed by in vitro and in vivo investigations. Pressure gradient/flow curves constructed from experimental data indicate that the valve does not present much obstruction even at high flow rates. Data obtained by post-operative catheterization of patients with prostheses suggest that these relations still hold when the valve is functioning in the human heart, and that the left atrial pressure is not greatly increased by conditions that simulate severe exercise. Experimental observation showed that the valve trapdoor took only $15 \mathrm{msec}$. to close, and left ventricular angiograms and dye curves confirmed that the valve was competent under its working conditions. Two patients who developed post-operative mitral incompetence did so as a result of stitches tearing out around the mitral valve ring. Attention is drawn to the curious lack of systolic murmurs in these patients: even when the valve mechanism itself was rendered grossly incompetent, no murmur appeared. Cine-angiograms confirmed that the valve trapdoor did not remain in the ventricle during systole, and did not interfere with the mechanics of ventricular systole. Due to its design, the position of the Mark II valve in the mitral valve ring was critical to diastolic filling, and this was clearly illustrated by the angiogram in one patient. It is concluded that the mechanical features of this valve make it an acceptable substitute for a damaged natural mitral valve.

Thanks are due to Professor J. F. Goodwin, Professor H. H. Bentall, and Mr. W. P. Cleland for their advice and encouragement throughout this study. The illustrations were prepared by Portland Plastics, Ltd., Hythe, Kent, from whom the Hammersmith mitral valve prosthesis is commercially available.

\section{REFERENCES}

Faber, J. J. (1964). Origin and conduction of the mitra sound in the heart. Cinculat. Res., 14, 426. 
Hughes, R. K. (1965). Complications of Starr-Edwards mitral valve replacement. $\mathcal{F}$. thorac. cardiovasc. Surg., 49, 731.

Kezdi, P., Head, L. R., and Buck, B. A. (1964). Mitral ballvalve prosthesis. Dynamic and clinical evaluation. Circulation, 30, 55.

Lombard, W. P., and Cope, O. M. (1919). Effect of pulse rate on the length of the systoles and diastoles of the normal human heart in the standing position. Amer. f. Physiol., 49, 139.
McMillan, I. K. R. (1955). Aortic stenosis. A post-mortem cinephotographic study of valve action. Brit. Heart f., $17,56$.

Melrose, D. G., Bentall, H. H., McMillan, I. K. R., Flege, J. B., Alvarez Diaz, F. R., Nahas, R. A., Fautley, R., and Carson, J. (1964). The evolution of a mitralvalve prosthesis. Lancet, 2, 623.

Morrow, A. G., Clark, W. D., Harrison, D. C., and Braunwald, E. (1964). Prosthetic replacement of the mitral valve. Circulation, 29, Suppl. 1, p. 2. 